\title{
Psychological Distress and Resilience among Partners of Cancer Patients Receiving Outpatient Chemotherapy
}

\author{
Noriko Ishizuka1*, Toshimi Takano, ${ }^{1,2}$, Yuji Miura², Koichi Suyama², Akihiko Shimomura ${ }^{2,3}$, \\ Eisuke Matsushima ${ }^{1}$

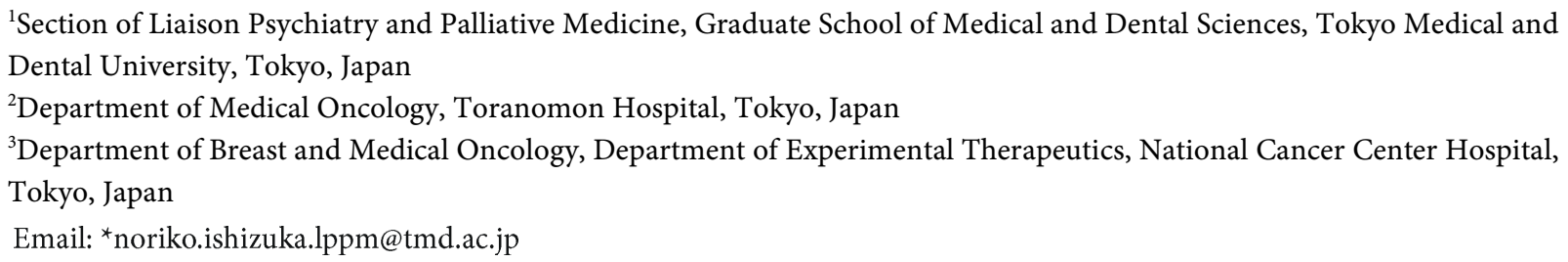

How to cite this paper: Ishizuka, N., Takano, T., Miura, Y., Suyama, K., Shimomura, A. and Matsushima, E. (2017) Psychological Distress and Resilience among Partners of Cancer Patients Receiving Outpatient Chemotherapy. International Journal of Clinical Medicine, 8, 481-495.

https://doi.org/10.4236/ijcm.2017.88045

Received: July 6, 2017

Accepted: August 8, 2017

Published: August 11, 2017

Copyright $\odot 2017$ by authors and Scientific Research Publishing Inc. This work is licensed under the Creative Commons Attribution International License (CC BY 4.0).

http://creativecommons.org/licenses/by/4.0/

\begin{abstract}
Background: Partners of cancer patients are at elevated risk of experiencing psychological distress. Psychological distress is known to be countered by the protective factor, resilience. The relationship between psychological distress and resilience among partners of cancer patients remains to be examined by quantitative studies. We aimed to investigate the association between psychological distress, and resilience and cancer-related psychological experience among partners of cancer patients receiving outpatient chemotherapy. Methods: Spouses and significant others of cancer patients were consecutively recruited into our cross-sectional study. The primary outcome was psychological distress, as assessed by the Hospital Anxiety and Depression Scale. The primary explanatory variables were resilience, as assessed by the short Japanese version of the Resilience Scale, and cancer-related psychological experience. Traumatic stress was assessed by the Japanese-language version of the Impact of Event Scale-Revised, while perception of caregiving burden and patients' symptoms, and psychological support needs were assessed by single-item questions. To examine the association between psychological distress, and resilience and partners' psychological experience, hierarchical multiple regression analysis was applied. Results: Psychological distress was evident in 33 of 109 partners, (30.3\%, 95\% confidence interval, 21.5 - 39.1). After adjusting for potential confounders, hierarchical multiple regression analysis showed the main effect of resilience. In the final step, while resilience was not found to be significant, psychological distress was observed to be positively
\end{abstract}


associated with traumatic stress and perceived caregiving burden $(\beta=0.64, \mathrm{p}$ $<0.000 ; \beta=0.22, \mathrm{p}<0.000$, respectively). These two variables explained $72.2 \%$ of the variance in psychological distress. Conclusions: The protective effect of resilience on partners' psychological distress is moderated by traumatic stress and perceived caregiving burden during patients' chemotherapy. The findings of this study suggest that a systematic way of providing appropriate psychological service to appropriate partners of cancer patients is required.

\section{Keywords}

Cancer, Partner, Psychological Distress, Resilience, Chemotherapy

\section{Introduction}

Spouses and significant others of cancer patients (termed "partners" in this study) are at elevated risk of experiencing psychological distress, such as depression and anxiety [1] [2] [3] [4]. The prevalence of depression in partners of cancer patients is approximately three times higher than that of the general population (30\% in partners vs. $11 \%$ in the general population) [1]. Psychological distress experienced by partners has a large impact on entire families, not only on the patients and partners themselves. Psychological distress in partners has been shown to increase both the risk of depression in patients [5] [6] [7] [8] and the risk of reduced family income [9].

Factors known to be associated with partners' psychological distress are female gender [4] [10] and younger age [11]. In addition to these demographic factors, cancer-related psychological experiences also affect partners' psychological distress. Partners' psychological distress has also been found to be associated with intrusion, a psychological reaction to stress characterized by unbidden thoughts and images, troubled dreams, strong pangs or waves of feelings, and repetitive behavior [5] [12]. Partners' psychological distress is also known to be affected by perceived caregiving burden during patient treatment. Partners with a negative perception of caregiving are more depressed than those who do not perceive caregiving negatively [2] [13]. Similarly, a higher level of psychological distress has been observed in partners who appraise patient treatment as stressful than that in those who appraise treatment positively [14]. Furthermore, partners' anxiety is reportedly predicted by unmet emotional and spiritual needs [15].

Unlike these risk factors, resilience protects against psychological distress. Resilience is an important component that determines individuals' reactions to personal stress and their coping strategies [16]. Additionally, resilience may be viewed as a defense mechanism that enables people to thrive in the face of adversity [17]. Higher resilience has been indicated by some studies about cancer patients to be related to lower psychological distress [18] [19]. However, the relationship between resilience and psychological distress among partners has not been examined quantitatively. Consequently, little is known about not only 
whether resilience directly affects partners' psychological distress but also whether resilience can function in protecting partners' mental health even in adversity, such as encounters with risk factors shown in current evidences. When patients are receiving chemotherapy, partners may experience great distress because they feel that is difficult to deal with patients' side effects [20], and participation in social activities decreases [9]. Therefore, the psychological distress experienced by partners of patients who receive chemotherapy needs to be examined carefully. Understanding the mechanism of the relationship between psychological distress and resilience may help with devising and implementing practical interventions in daily clinical settings and with ensuring partners experiencing psychological distress receive attention in a timely manner.

Therefore, we aimed to investigate the association between psychological distress and resilience, and also to investigate the influence of cancer-related psychological experiences on relationship between psychological distress and resilience among partners of cancer patients receiving outpatient chemotherapy.

\section{Methods}

\subsection{Study Design}

In this cross-sectional study, partners of cancer patients receiving outpatient chemotherapy were consecutively recruited between July 2012 and March 2014. The participants completed a self-administered questionnaire survey at the Department of Medical Oncology at Toranomon Hospital in Tokyo, Japan (approximately 2000 chemotherapy sessions are carried out on outpatients per year, and the number of admission is approximately 370 per year). Toranomon Hospital is the general hospital founded by Federation of National Public Service Personnel Mutual Aid Associations, which has 868 beds and approximately 2700 outpatients per day. This study was approved by the Medical Research Ethics Committee of Tokyo Medical and Dental University (1322) and the Institutional Review Board and Ethics Committee of Toranomon Hospital (595). Written informed consent was obtained from all partners who participated in the study.

\subsection{Participants and Procedures}

Eligible participants were partners who were married or in a common law relationship with a patient with cancer, informed about the diagnosis, aged $\geq 20$ years, and able to complete the self-administered questionnaire in Japanese. Patients or partners who visited the hospital were approached by a researcher (NI), the patient's oncologists (TT/YM/KS/AS), or two clinical research coordinators (HS/KN) during or after consultation. All patients provided oral informed consent prior to approaching partners. Patients or partners received a stamped addressed envelope containing the questionnaire and consent form. Partners completed the questionnaire and returned it either directly or by mail to the hospital. The questionnaire was anonymous to minimize response bias.

Among a total of 171 eligible participants, 122 partners returned the ques- 
tionnaire, and one declined consent (response rate: 70.8\%). After excluding participants who had more than $50 \%$ missing data on any of the three psychological scales following the recommendation [21], 109 partners were included in the analyses (valid response rate: 63.7\%). Sample size was determined from the recommendation for multiple regression analysis [22]. The recommendation showed that 104 participants were appropriate for power level of 0.8 , at an alpha level of 0.05 , medium effect size, and seven independent variables, suggesting that our study sample of 109 was sufficient. The participant inclusion process is shown in Figure 1.

\subsection{Measures}

Data on partners' demographic characteristics and patients' medical information were collected from partners. We also assessed partners' characteristics including psychological distress, resilience, and cancer-related psychological experience (i.e., traumatic stress, perception of caregiving burden and patients' symptoms, and psychological support needs).

\section{Partners' demographic and patients' disease characteristics}

Partners' demographic variables included age, sex, employment status, education level, duration of marriage/cohabitation, whether they had dependent children ( $<20$ years), and the person who received the questionnaire. Partners were also asked whether they were receiving treatment for any illness: "Do you have any illness for which you receive treatment currently?" (possible responses

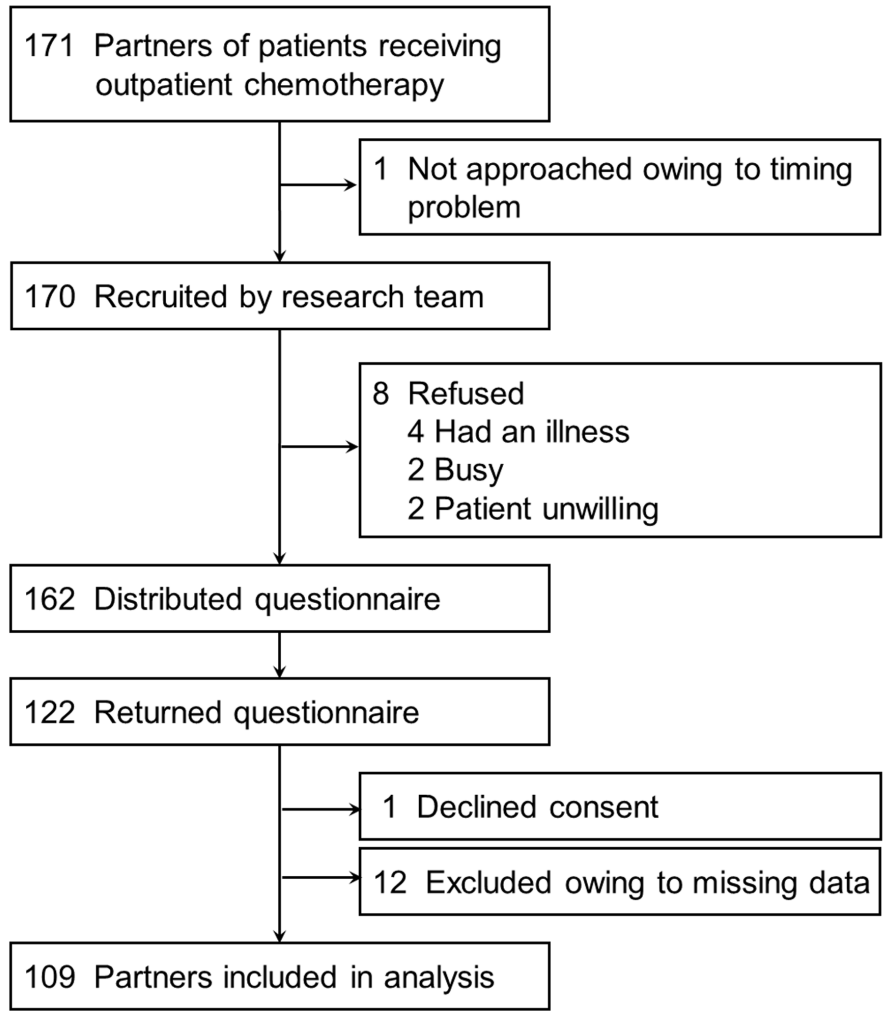

Figure 1. Flow diagram of the participant inclusion process. 
were "yes" or "no"). Patients' disease characteristics included cancer site, cancer stage, disease status, years since diagnosis, first treatment, treatment type, duration of current treatment, and prior experience of chemotherapy.

\section{Psychological distress}

To assess psychological distress, the Japanese version of the Hospital Anxiety and Depression Scale (HADS) [23] [24] was used as the primary outcome. This 14-item scale is widely used to measure anxiety and depression in cancer patients and partners. The total scores range from 0 to 42 , with higher scores indicating greater psychological distress. We used a cut-off point of 14/15 to classify psychological distress. Previously, this cut-off point was determined in accordance with the Structured Clinical Interview for the Diagnostic and Statistical Manual of Mental Disorders (3rd ed., rev.; DSM-III-R) for diagnosing adjustment disorder and/or major depressive disorder in Japanese cancer patients (sensitivity, 72.2; specificity, 81.4) [25]. Cronbach's alpha for the total score was 0.90 in this study.

\section{Resilience}

Resilience was assessed using the short Japanese version of the Resilience Scale (RS-14) [26] [27]. The RS-14 measures the degree of individual resilience. The scale consists of 14 items, with total scores ranging from 14 to 98 . Higher scores indicate greater resilience. In the present study, Cronbach's alpha was 0.95.

\section{Cancer-related psychological experience}

\section{Traumatic Stress}

We used the Japanese-language version of the Impact of Event Scale-Revised (IES-R-J) [28] [29] to assess cancer-related traumatic stress with three subscales measuring intrusion, avoidance, and hyperarousal. This scale contains 22 items, with total scores ranging from 0 to 88 . Higher scores indicate greater traumatic stress. Cronbach's alpha in the present study was 0.95 .

Perceived caregiving burden and patients' symptoms, and psychological support needs

We assessed perceived caregiving burden and patients' symptoms, and psychological support needs using single-item questions. The caregiving burden including housework and patient care was rated using the Visual Analog Scale ranging from 0 (none) to 10 (most severe), with the following instruction: "Please rate the current degree of your burden of housekeeping and/or caring for your partner using the following scale. Higher scores indicate severe burden." Partners were also asked whether there were symptoms in the patient for which they themselves felt pain, i.e., "Are there any symptoms for which you are feeling pain among the symptoms currently appearing in your partner?", and whether they needed psychological support, i.e., "Do you think you need psychological support?" (possible responses for both questions were “yes” or “no”).

\subsection{Statistical Analysis}

After excluding participants with more than $50 \%$ of missing data on either the 
HADS, the IES-R-J, or the RS-14, mean values of each item were substituted for the remaining missing items.

Descriptive statistics were calculated for partners' demographic and patients' disease characteristics, and partners' psychological variables including prevalence of partners' psychological distress.

Simple regression analyses were used to examine the association between psychological distress, and demographic and disease variables. Hierarchical multiple regression analysis was used to examine the association between psychological distress, and resilience and partners' psychological experience. In step 1, age, sex, and variables that were shown to be statistically significant in simple regression analyses were simultaneously entered into the model as potential confounders. Age [11] and sex [4] [10] were chosen based on previous literature. In step 2, resilience was entered to examine its main effect on psychological distress. In step 3, variables of cancer-related partners' psychological experience were entered to examine whether resilience functions even in adversity.

The confidence limits were set at 95\%. For all analyses, SPSS Statistics 17.0 (SPSS Inc., Chicago, IL, USA) was used.

\section{Results}

\subsection{Partner Characteristics}

Partners' demographic characteristics and patients' disease characteristics differed statistically between the included and excluded groups for duration of marriage/cohabitation, being treated for illness, cancer site, disease status, and first treatment. Duration of marriage/cohabitation was shorter in the included group than in the excluded group. For the other variables, less data were missing in the included group than in the excluded group.

Table 1 shows partner demographic characteristics and Table 2 shows patient disease characteristics. The median age of partners was 62.5 years (interquartile range, 53.0 - 68.0). Most partners were men (67.0\%), were employed (60.6\%), and held a bachelor's degree or higher (61.5\%). Approximately half of the cancer patients had breast cancer $(46.8 \%)$, were in stage III or IV $(45.9 \%)$, and had an illness duration of $<1$ year $(51.4 \%)$.

\subsection{Descriptive Statistics of Partners' Psychological Variables}

Of 109 partners, approximately one third (30.3\%, 95\% confidence interval [CI], 21.5 - 39.1) exhibited psychological distress with a cut-off point of 15 or higher (Table 3). The mean score of HADS was 11.7 (standard deviation [SD] = 7.2), ranging from 0 to 29 . The mean scores of RS-14 and IES-R-J were 68.0 (SD = 14.7; range 25 - 95) and 19.3 ( $\mathrm{SD}=14.5$; range 0 - 59), respectively. The median value of caregiving burden was 3.0 (interquartile range, 1.0 - 5.0). Most partners felt pain among the symptoms that appeared in their patient (65.1\%), and approximately one third thought they needed psychological support (28.4\%) (Table 3). 


\subsection{Association of Demographic and Disease Variables, Resilience, and Psychological Experience on Psychological Distress}

In simple regression analyses examining the association between psychological distress, and demographic and disease variables, only the recipient of the questionnaire was statistically significant $(B=3.13, p=0.03)$; partner recipient was significantly associated with higher psychological distress than patient recipient.

Table 1. Partner demographic characteristics $(\mathrm{N}=109)$.

\begin{tabular}{|c|c|c|}
\hline \multirow{2}{*}{$\begin{array}{c}\text { Characteristics } \\
\text { Age }^{\mathrm{a}}, \text { median (IQR), years }\end{array}$} & \multicolumn{2}{|c|}{ No. (\%) of partners } \\
\hline & 62.5 & $(53-68)$ \\
\hline Missing & 5 & $(4.6)$ \\
\hline \multicolumn{3}{|l|}{$\operatorname{Sex}^{\mathrm{a}}$} \\
\hline Male & 73 & $(67.0)$ \\
\hline Female & 35 & $(32.1)$ \\
\hline Missing & 1 & $(0.9)$ \\
\hline \multicolumn{3}{|l|}{ Employment status } \\
\hline Employed & 66 & $(60.6)$ \\
\hline Retired/unemployed & 18 & $(16.5)$ \\
\hline Homemaker & 22 & $(20.2)$ \\
\hline Missing & 3 & $(2.8)$ \\
\hline \multicolumn{3}{|l|}{ Education level } \\
\hline Less than bachelor's degree & 40 & $(36.7)$ \\
\hline Bachelor's degree or higher & 67 & $(61.5)$ \\
\hline Missing & 2 & $(1.8)$ \\
\hline \multicolumn{3}{|l|}{ Duration of marriage/cohabitation } \\
\hline Median (IQR), year(s) & 34.0 & $(24-42)$ \\
\hline Missing & 3 & $(2.8)$ \\
\hline \multicolumn{3}{|l|}{ Dependent children ( $<20$ years) } \\
\hline Yes & 20 & $(18.3)$ \\
\hline No & 86 & $(78.9)$ \\
\hline Missing & 3 & $(2.8)$ \\
\hline \multicolumn{3}{|l|}{ Partner being treated for illness } \\
\hline Yes & 43 & $(39.4)$ \\
\hline No & 65 & $(59.6)$ \\
\hline Missing & 1 & $(0.9)$ \\
\hline \multicolumn{3}{|l|}{ Recipient of the questionnaire ${ }^{a}$} \\
\hline Patient & 72 & $(66.1)$ \\
\hline Partner & 37 & $(33.9)$ \\
\hline
\end{tabular}

Abbreviation: IQR, interquartile range. ${ }^{\mathrm{a}}$ Marked variables were entered in the regression analysis simultaneously as potential confounders. 
Table 2. Patient disease characteristics reported by partners $(\mathrm{N}=109)$.

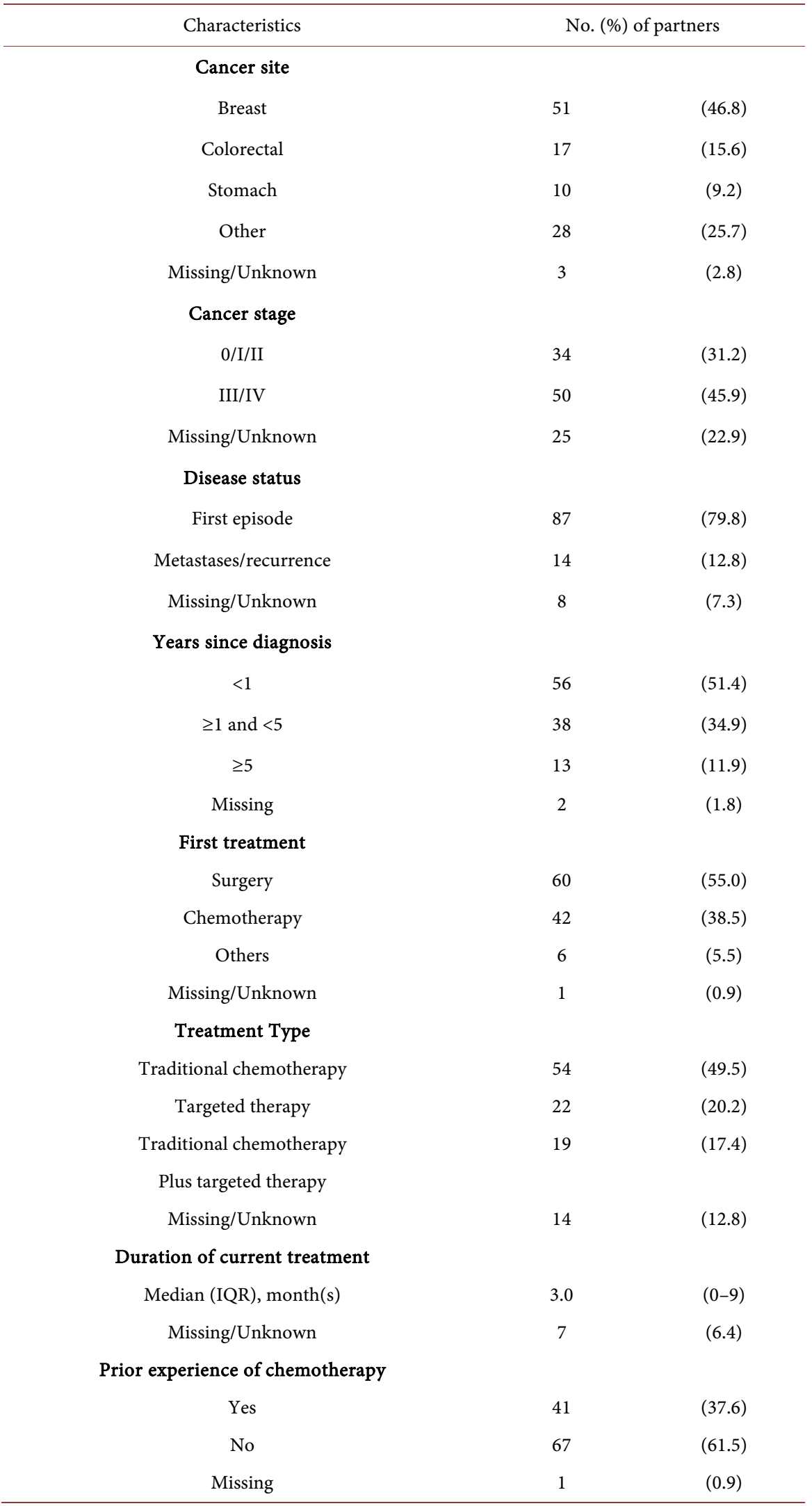

Abbreviation: IQR, interquartile range. 
Table 3. Descriptive statistics of partners' psychological variables $(\mathrm{N}=109)$.

\begin{tabular}{|c|c|c|c|}
\hline Variables & \multicolumn{3}{|c|}{ No. (\%) of partners } \\
\hline \multicolumn{4}{|l|}{ Psychological distress } \\
\hline HADS, mean (SD), range & 11.7 & (7.2) & $0-29$ \\
\hline Positive $(\geq 15)$ & 33 & $(30.3)$ & \\
\hline Negative $(<15)$ & 76 & $(69.7)$ & \\
\hline \multicolumn{4}{|l|}{ Resilience } \\
\hline RS-14, mean (SD), range & 68.0 & $(14.7)$ & $25-95$ \\
\hline \multicolumn{4}{|c|}{ Cancer-related psychological experience } \\
\hline \multicolumn{4}{|l|}{ Traumatic stress } \\
\hline IES-R-J, mean (SD), range & 19.3 & $(14.5)$ & $0-59$ \\
\hline \multicolumn{4}{|l|}{ Perceived caregiving burden ${ }^{\mathrm{a}}$} \\
\hline Median (IQR) & 3.0 & $(1-5)$ & \\
\hline Missing & 3 & $(2.8)$ & \\
\hline \multicolumn{4}{|c|}{ Presence of painful symptoms in the patient } \\
\hline Yes & 71 & $(65.1)$ & \\
\hline No & 38 & $(34.9)$ & \\
\hline \multicolumn{4}{|l|}{ Psychological support needs } \\
\hline Yes & 31 & $(28.4)$ & \\
\hline No & 78 & (71.6) & \\
\hline
\end{tabular}

Abbreviations: HADS, the Hospital Anxiety and Depression Scale; IES-R-J, the Japanese-language version of the Impact of Event Scale-Revised; IQR, interquartile range; RS-14, the short Japanese version of the Resilience Scale; SD, standard deviation. ${ }^{a}$ Assessed using the Visual Analog Scale (range $=0$ - 10).

A summary of hierarchical multiple regression analysis for partners' psychological distress is shown in Table 4. In step 1, partner recipient was associated with higher psychological distress $(\beta=0.31, \mathrm{p}=0.003)$. In step 2 , a significant association was shown between higher resilience and lower psychological distress $(\beta=-0.39, \mathrm{p}<0.000)$, and partner recipient was significantly associated with higher psychological distress $(\beta=0.28, \mathrm{p}=0.004)$. In step 3 , higher traumatic stress and severer caregiving burden were significantly associated with higher psychological distress $(\beta=0.64, \mathrm{p}<0.000 ; \beta=0.22, \mathrm{p}<0.000$, respectively). Resilience, presence of painful symptoms in the patient, and psychological support needs were not observed to be significant. Traumatic stress and caregiving burden explained $72.2 \%$ of the variance in psychological distress.

\section{Discussion}

This study showed that the prevalence of psychological distress was 30.3\% among partners of cancer patients receiving outpatient chemotherapy. To the best of our knowledge, only four studies have investigated the prevalence of psychological distress among spouses and significant others of patients undergoing cancer treatment, with a reported prevalence of $30.5 \%-38.9 \%$ [1] [2] [3] 
Table 4. Hierarchical regression analysis for partners' psychological distress $(\mathrm{N}=101)$.

\begin{tabular}{|c|c|c|c|c|c|c|c|}
\hline Partner psychological experience & Reference & \multicolumn{2}{|c|}{$\mathrm{B}(\mathrm{SE})$} & \multicolumn{3}{|c|}{$95 \% \mathrm{CI}$} & $\beta$ \\
\hline \multicolumn{8}{|l|}{ Step 1} \\
\hline Age & & -0.04 & $(0.06)$ & -0.16 & - & 0.08 & -0.06 \\
\hline Sex & Male & 0.65 & $(1.48)$ & -2.29 & - & 3.59 & 0.04 \\
\hline Recipient of the questionnaire & Patient & 4.47 & $(1.48)$ & 1.53 & - & 7.42 & $0.31^{*}$ \\
\hline \multicolumn{8}{|l|}{ Intercept $=11.28 ; \mathrm{R}^{2}=0.09^{*} ;$ Adjusted $\mathrm{R}^{2}=0.06$} \\
\hline \multicolumn{8}{|l|}{ Step 2} \\
\hline Age & & 0.00 & $(0.06)$ & -0.11 & - & 0.12 & 0.00 \\
\hline Sex & Male & -0.31 & $(1.38)$ & -3.06 & - & 2.43 & -0.02 \\
\hline Recipient of the questionnaire & Patient & 4.05 & $(1.37)$ & 1.34 & - & 6.77 & $0.28^{*}$ \\
\hline Resilience & & -0.19 & $(0.04)$ & -0.27 & - & -0.10 & $-0.39^{*}$ \\
\hline \multicolumn{8}{|c|}{ Intercept $=22.77 ; \mathrm{R}^{2}=0.24^{*} ;$ Adjusted $\mathrm{R}^{2}=0.21 ; \Delta \mathrm{R}^{2}=0.15^{\star}$} \\
\hline \multicolumn{8}{|l|}{ Step 3} \\
\hline Age & & -0.01 & $(0.04)$ & -0.08 & - & 0.06 & -0.02 \\
\hline Sex & Male & -0.71 & $(0.83)$ & -2.36 & - & 0.94 & -0.05 \\
\hline Recipient of the questionnaire & Patient & 1.06 & $(0.85)$ & -0.63 & - & 2.75 & 0.07 \\
\hline Resilience & & -0.02 & $(0.03)$ & -0.08 & - & 0.04 & -0.04 \\
\hline Traumatic stress & & 0.31 & $(0.03)$ & 0.25 & - & 0.38 & $0.64^{*}$ \\
\hline Perceived caregiving burden & & 0.67 & $(0.18)$ & 0.30 & - & 1.03 & $0.22^{*}$ \\
\hline Presence of painful symptoms in the patient & No & 1.68 & $(0.85)$ & -0.01 & - & 3.37 & 0.12 \\
\hline Psychological support needs & No & 0.88 & $(0.90)$ & -0.91 & - & 2.67 & 0.06 \\
\hline Intercept $=4.49 ; \mathrm{R}^{2}=0.74^{\star} ;$ Adjusted $\mathrm{R}^{2}=0.72 ; \Delta \mathrm{R}^{2}$ & & & & & & & \\
\hline
\end{tabular}

Abbreviations: $\mathrm{B}$, unstandardized regression coefficients; $\beta$, standardized regression coefficients; $\mathrm{CI}$, confidence interval; $\mathrm{R}^{2}$, multiple coefficient of determination; SE, standard error; $\Delta \mathrm{R}^{2}$, change in multiple coefficient of determination. ${ }^{*} p<0.05$.

[4]. The prevalence observed in these previous studies is almost the same as that observed in our study. The concordance of prevalence may be a reflection of similarities in the study setting and patient clinical characteristics. Most of these studies were conducted in an outpatient setting, and included a high proportion of partners whose patients were receiving chemotherapy (68\% - 94\%) [1] [3] [4].

The hierarchical regression analysis showed a significant association between greater resilience and lower psychological distress in step 2. However, in step 3, greater traumatic stress and severer perception of caregiving burden were strongly associated with higher psychological distress, and resilience was no longer significant. This result indicates that resilience plays a protective role against partners' psychological distress, but that it does not function in the face of certain types of adversity. Conversely, resilience is also known to give people the ability to bounce back from hardship and trauma [30]. Therefore, the effect of resilience on psychological distress may be temporarily moderated by facing adversity, which may in turn help individuals recover from adversity afterwards. 
To illustrate the trajectory of the function of resilience among partners of cancer patients, longitudinal studies are needed [16].

Contrary to expectation, the presence of painful symptoms in patients was not statistically significantly associated with partners' psychological distress in the hierarchical regression analysis, despite $65.1 \%$ of partners having reported the presence of painful symptoms in the patient. This result did not agree with findings reported in a previous study; the level of psychological distress was higher in partners who had negative perceptions regarding patients' treatment than in partners who had positive perceptions [14]. A possible explanation for this result is that the partners in our study tended to regard patients' side effects as evidence of a drug's positive effect [31]. Because of this perception, partners' psychological distress was not affected by the presence of patient symptoms, even if partners perceived these symptoms as painful.

Likewise, psychological support needs were not found to be a statistically significantly associated with partners' psychological distress. This result was inconsistent with the findings of a previous study [15]. This disagreement can be explained by differences in contents of caregiving burden that were examined simultaneously in the analysis. The previous study used consequence of caregiving (e.g., disrupted schedule) to represent caregiving burden, whereas we directly asked partners about the intensity of caregiving burden related to housework and patient care. The results of our study indicate that partners tend to prioritize patients' needs over that of partners', as described in a qualitative study of family caregivers [32]. In other words, partners experiencing psychological distress possibly do not always express their needs for psychological support even if they need it. Therefore, partners who show reluctance in receiving psychological support need attention.

From a clinical perspective, delivering appropriate psychosocial services to partners who need support is a key issue [33]. Some researchers have reported on low treatment rates for partners experiencing psychological distress [10] [34] [35]; also indicating the importance of an early approach to partner distress [35]. To find partners who are in need of psychological support in a timely manner, we recommend screening for partners' psychological distress using a multi-step approach, in which a very brief and non-invasive question is used as a first step [36] [37]. Findings of the current study indicate that a simple questionnaire focused on partners' traumatic stress and/or perception of caregiving burden should be administered before conducting precise screening for partners with suspected psychological distress. Identifying appropriate question items in future studies is also necessary for practical use. With respect to psychological services, the findings of the current study suggest that intervention, regardless of its form, should be aimed at enhancing resilience that is suitable for partners' psychological distress during patients' chemotherapy, such as focusing on improving coping skills [38]. This is because resilience mediates the association between coping skills and psychological distress [39]. Effective coping skills and methods 
specifically targeting partners of cancer patients receiving chemotherapy should also be examined in future study.

The current study has several limitations. First, its cross-sectional design did not allow us to draw conclusions regarding causality. Second, the small sample size may have limited the conclusiveness of our results. Although a significant association was shown, further research is necessary because of uncertainties. Third, we used a self-report instrument to assess psychological distress instead of a standardized clinical interview; therefore, the prevalence estimated in the current study cannot be assumed to represent a diagnosis of psychiatric disorder. Finally, the single-center study design limits generalizability to other populations with different demographics or from other hospitals. The hospital where our study was conducted is located in the center of Tokyo, Japan. This specificity may have introduced selection bias, such as the sampling of participants with high levels of education and income.

\section{Conclusion}

This study revealed that the protective effect of resilience on partners' psychological distress is moderated by cancer-related partners' negative psychological experience, i.e., traumatic stress and perceived caregiving burden when patients are receiving outpatient chemotherapy. Furthermore, partners with psychological distress do not always seek psychological support. These findings suggest the necessity of a systematic way to provide appropriate psychological services to partners of cancer patients.

\section{Acknowledgements}

We are grateful to Ms. Hitomi Sato, Ms. Kiyomi Nonogaki, and Ms. Eriko Ozeki for their valuable assistance, including with participant recruitment. We thank all the staff in the outpatient unit at Toranomon Hospital for their cooperation with the survey. We also thank Edanz Group (www.edanzediting.com) for editing a draft of this manuscript.

\section{Conflict of Interest}

The authors declare no conflict of interest.

\section{References}

[1] Bigatti, S.M., Wagner, C.D., Lydon-Lam, J.R., Steiner, J.L. and Miller, K.D. (2011) Depression in Husbands of Breast Cancer Patients: Relationships to Coping and Social Support. Supportive Care in Cancer, 19, 455-466. https://doi.org/10.1007/s00520-010-0835-8

[2] Braun, M., Mikulincer, M., Rydall, A., Walsh, A. and Rodin, G. (2007) Hidden Morbidity in Cancer: Spouse Caregivers. Journal of Clinical Oncology, 25, 48294834. https://doi.org/10.1200/JCO.2006.10.0909

[3] Haun, M.W., Sklenarova, H., Villalobos, M., Thomas, M., Brechtel, A., Löwe, B., Herzog, W. and Hartmann, M. (2014) Depression, Anxiety and Disease-Related 
Distress in Couples Affected by Advanced Lung Cancer. Lung Cancer, 86, 274-280. https://doi.org/10.1016/j.lungcan.2014.09.009

[4] Moser, M.T., Künzler, A., Nussbeck, F., Bargetzi, M. and Znoj, H.J. (2013) Higher Emotional Distress in Female Partners of Cancer Patients: Prevalence and $\mathrm{Pa}$ tient-Partner Interdependencies in a 3-Year Cohort. Psycho-Oncology, 22, 2693 2701. https://doi.org/10.1002/pon.3331

[5] Baider, L., Koch, U., Esacson, R. and De-Nour, A.K. (1998) Prospective Study of Cancer Patients and Their Spouses: The Weakness of Marital Strength. PsychoOncology, 7, 49-56.

https://doi.org/10.1002/(SICI)1099-1611(199801/02)7:1<49::AID-PON312>3.0.CO; $\underline{2-Z}$

[6] Carmack Taylor, C.L., Badr, H., Lee, J.H., Fossella, F., Pisters, K., Gritz, E.R. and Schover, L. (2008) Lung Cancer Patients and Their Spouses: Psychological and Relationship Functioning within 1 Month of Treatment Initiation. Annals of Behavioral Medicine, 36, 129-140. https://doi.org/10.1007/s12160-008-9062-7

[7] Dorros, S.M., Card, N.A., Segrin, C. and Badger, T.A. (2010) Interdependence in Women with Breast Cancer and Their Partners: An Inter-Individual Model of Distress. Journal of Consulting and Clinical Psychology, 78, 121-125. https://doi.org/10.1037/a0017724

[8] Drabe, N., Klaghofer, R., Weidt, S., Zwahlen, D., Büchi, S. and Jenewein, J. (2015) Mutual Associations between Patients' and Partners' Depression and Quality of Life with Respect to Relationship Quality, Physical Complaints, and Sense of Coherence in Couples Coping with Cancer. Psycho-Oncology, 24, 442-450. https://doi.org/10.1002/pon.3662

[9] Mosher, C.E., Champion, V.L., Azzoli, C.G., Hanna, N., Jalal, S.I., Fakiris, A.J., Birdas, T.J., Okereke, I.C., Kesler, K.A., Einhorn, L,H., Monahan, P.O. and Ostroff, J.S. (2013) Economic and Social Changes among Distressed Family Caregivers of Lung Cancer Patients. Supportive Care in Cancer, 21, 819-826. https://doi.org/10.1007/s00520-012-1585-6

[10] Bishop, M.M., Beaumont, J.L., Hahn, E.A., Cella, D., Andrykowski, M.A., Brady, M.J., Horowitz, M.M., Sobocinski, K.A., Rizzo, J.D. and Wingard, J.R. (2007) Late Effects of Cancer and Hematopoietic Stem-Cell Transplantation on Spouses or Partners Compared with Survivors and Survivor-Matched Controls. Journal of Clinical Oncology, 25, 1403-1411. https://doi.org/10.1200/JCO.2006.07.5705

[11] Manne, S.L., Ostroff, J.S., Norton, T.R., Fox, K., Goldstein, L. and Grana, G. (2006) Cancer-Related Relationship Communication in Couples Coping with Early Stage Breast Cancer. Psycho-oncology, 15, 234-247. https://doi.org/10.1002/pon.941

[12] Horowitz, M., Wilner, N. and Alvarez, W. (1979) Impact of Event Scale: A Measure of Subjective Stress. Psychosomatic Medicine, 41, 209-218. https://doi.org/10.1097/00006842-197905000-00004

[13] Nijboer, C., Tempelaar, R., Triemstra, M., van den Bos, G.A. and Sanderman, R. (2001) The Role of Social and Psychologic Resources in Caregiving of Cancer Patients. Cancer, 91, 1029-1039. https://doi.org/10.1002/1097-0142(20010301)91:5<1029::AID-CNCR1094>3.0.CO;2 $\underline{-1}$

[14] Keitel, M.A., Zevon, M.A., Rounds, J.B., Petrelli, N.J. and Karakousis, C. (1990) Spouse Adjustment to Cancer Surgery: Distress and Coping Responses. Journal of Surgical Oncology, 43, 148-153. https://doi.org/10.1002/jso.2930430305

[15] Perz, J., Ussher, J.M., Butow, P. and Wain, G. (2011) Gender Differences in Cancer 
Carer Psychological Distress: An Analysis of Moderators and Mediators. European Journal of Cancer Care, 20, 610-619. https://doi.org/10.1111/j.1365-2354.2011.01257.x

[16] Connor, K.M. (2006) Assessment of Resilience in the Aftermath of Trauma. Journal of Clinical Psychiatry, 67, 46-49.

[17] Davydov, D.M., Stewart, R., Ritchie, K. and Chaudieu, I. (2010) Resilience and Mental Health. Clinical Psychology Review, 30, 479-495. https://doi.org/10.1016/j.cpr.2010.03.003

[18] Matzka, M., Mayer, H., Köck-Hódi, S., Moses-Passini, C., Dubey, C., Jahn, P., Schneeweiss, S. and Eicher, M. (2016) Relationship between Resilience, Psychological Distress and Physical Activity in Cancer Patients: A Cross-Sectional Observation Study. PLOS ONE, 11, e0154496. https://doi.org/10.1371/journal.pone.0154496

[19] Tian, J. and Hong, J.S. (2014) Assessment of the Relationship between Resilience and Quality of Life in Patients with Digestive Cancer. World Journal of Gastroenterology, 20, 18439-18444. https://doi.org/10.3748/wjg.v20.i48.18439

[20] Sercekus, P., Besen, D.B., Gunusen, N.P. and Edeer, D. (2014) Experiences of Family Caregivers of Cancer Patients Receiving Chemotherapy. Asian Pacific Journal of Cancer Prevention, 15, 5063-5069. https://doi.org/10.7314/APJCP.2014.15.12.5063

[21] Fayers, P.M. and Machin, D. (2000) Missing Data. In: Fayers, P.M. and Machin, D., Eds., Quality of Life: Assessment, Analysis and Interpretation, John Wiley \& Sons, Chichester, 224-247. https://doi.org/10.1002/0470846283.ch11

[22] Newton, R.R. and Rudestam, K.E. (1999) Chapter 10 Questions About Multiple Regression Analysis. In: Newton, R.R. and Rudestam, K.E., Eds., Your Statistical Consultant. Answers to Your Data Analysis Questions, Sage Publications, Inc., Thousands Oaks, 247-276.

[23] Kitamura, T. (1993) Hospital Anxiety and Depression Scale. Archives of Psychiatric Diagnostics and Clinical Evaluation, 4, 371-372.

[24] Zigmond, A.S. and Snaith, R.P. (1983) The Hospital Anxiety and Depression Scale. Acta Psychiatrica Scandinavica, 67, 361-370. https://doi.org/10.1111/j.1600-0447.1983.tb09716.x

[25] Kugaya, A., Akechi, T., Okuyama, T., Nakano, T., Mikami, I., Okamura, H. and Uchitomi, Y. (2000) Prevalence, Predictive Factors, and Screening for Psychologic Distress in Patients with Newly Diagnosed Head and Neck Cancer. Cancer, 88, 2817-2823. https://doi.org/10.1002/1097-0142(20000615)88:12<2817::AID-CNCR22>3.0.CO;2-N

[26] Nishi, D., Uehara, R., Kondo, M. and Matsuoka, Y. (2010) Reliability and Validity of the Japanese Version of the Resilience Scale and its Short Version. BMC Research Notes, 3, 310. https://doi.org/10.1186/1756-0500-3-310

[27] Wagnild, G.M. and Young, H.M. (1993) Development and Psychometric Evaluation of the Resilience Scale. Journal of Nursing Measurement, 1, 165-178.

[28] Asukai, N., Kato, H., Kawamura, N., Kim, Y., Yamamoto, K., Kishimoto, J., Miyake, Y. and Nishizono-Maher, A. (2002) Reliability and Validity of the Japanese-Language Version of the Impact of Event Scale-Revised (IES-R-J ): Four Studies of Different Traumatic Events. Journal of Nervous and Mental Disease, 190, 175-182. https://doi.org/10.1097/00005053-200203000-00006

[29] Weiss, D.S. and Marmar, C.R. (1997) The Impact of Event Scale-Revised. In: Wilson, J.P. and Keane, T.M., Eds., Assessing Psychological Trauma and PTSD, Guilford Press, New York, 399-411.

[30] Southwick, S.M. and Charney, D.S. (2012) The Science of Resilience: Implications 
for the Prevention and Treatment of Depression. Science, 338, 79-82. https://doi.org/10.1126/science.1222942

[31] American Society of Clinical Oncology (2015) Skin Reactions to Targeted Therapies.

http://www.cancer.net/navigating-cancer-care/side-effects/skin-reactions-targeted-t herapies

[32] Mosher, C.E., Given, B.A. and Ostroff, J.S. (2015) Barriers to Mental Health Service Use among Distressed Family Caregivers of Lung Cancer Patients. European Journal of Cancer Care, 24, 50-59. https://doi.org/10.1111/ecc.12203

[33] Northouse, L.L. and McCorkle, R. (2015) Spouse Caregivers of Cancer Patients. In: Holland, J.C., Breitbart, W.S., Butow P.N., Jacobsen, P.B., Loscalzo, M.J. and McCorkle, R., Eds., Psycho-Oncology, 3rd Edition, Oxford University Press, Oxford, New York, 567-573. https://doi.org/10.1093/med/9780199363315.003.0075

[34] Mosher, C.E., Champion, V.L., Hanna, N., Jalal, S.I., Fakiris, A.J., Birdas, T.J., Okereke, I.C., Kesler, K.A., Einhorn, L.H., Given, B.A., Monahan, P.O. and Ostroff, J.S. (2013) Support Service Use and Interest in Support Services among Distressed Family Caregivers of Lung Cancer Patients. Psycho-oncology, 22, 1549-1556.

https://doi.org/10.1002/pon.3168

[35] Vanderwerker, L.C., Laff, R.E., Kadan-Lottick, N.S., McColl, S. and Prigerson, H.G. (2005) Psychiatric Disorders and Mental Health Service Use among Caregivers of Advanced Cancer Patients. Journal of Clinical Oncology, 23, 6899-6907. https://doi.org/10.1200/JCO.2005.01.370

[36] Mitchell, A.J. (2010) Short Screening Tools for Cancer-Related Distress: A Review and Diagnostic Validity Meta-Analysis. Journal of the National Comprehensive Cancer Network, 8, 487-494. https://doi.org/10.6004/jnccn.2010.0035

[37] Mitchell, A.J. (2015) Screening and Assessment for Distress. In: Holland, J.C., Breitbart, W.S., Butow P.N., Jacobsen, P.B., Loscalzo, M.J. and McCorkle, R., Eds., Psycho-Oncology, 3rd Edition, Oxford University Press, Oxford, New York, 384 395. https://doi.org/10.1093/med/9780199363315.003.0048

[38] Molina, Y., Yi, J.C., Martinez-Gutierrez, J., Reding, K.W., Yi-Frazier, J.P. and Rosenberg, A.R. (2014) Resilience among Patients across the Cancer Continuum: Diverse Perspectives. Clinical Journal of Oncology Nursing, 18, 93-101. https://doi.org/10.1188/14.CJON.93-101

[39] Lim, J.W., Shon, E.J., Paek, M. and Daly, B. (2014) The Dyadic Effects of Coping and Resilience on Psychological Distress for Cancer Survivor Couples. Supportive Care in Cancer, 22, 3209-3217. https://doi.org/10.1007/s00520-014-2334-9 
Submit or recommend next manuscript to SCIRP and we will provide best service for you:

Accepting pre-submission inquiries through Email, Facebook, LinkedIn, Twitter, etc. A wide selection of journals (inclusive of 9 subjects, more than 200 journals)

Providing 24-hour high-quality service

User-friendly online submission system

Fair and swift peer-review system

Efficient typesetting and proofreading procedure

Display of the result of downloads and visits, as well as the number of cited articles Maximum dissemination of your research work

Submit your manuscript at: http://papersubmission.scirp.org/

Or contact ijcm@scirp.org 